\title{
The Anatomy of Rhododendron ponticum, L., and of Ilex Aquifolium, L., in Reference to Specific Conductivity.
}

BY

\author{
MAUD F. RIVETT, B.Sc.
}

With seventeen Diagrams in the Text.

THIS paper is the result of an investigation into the anatomical object of ascertaining the anatomical basis for variations in the water-conductivity of the wood.

In experimenting on the water-conducting efficiency of the wood in shrubs and trees, Professor Farmer has shown that not only are there great differences in the water-carrying powers of deciduous and evergreen trees and shrubs, but there may be also variation among the stems and branches of the same species when taken from plants growing under different conditions and in different localities. ${ }^{1}$

The term 'specific conductivity' is used to express the volume of water transmitted by a segment of stem, $15 \mathrm{~cm}$. in length, per I sq. $\mathrm{cm}$. of wood as seen in transverse section. This volume, given in cubic centimetres for the period of I 5 minutes, varied for 28 holly twigs from $6 \cdot 8$ up to I $2 \cdot 2$, with an average of 8.7 : for Rhododendron ponticum it varied for 50 stems from Io to 25 for the majority, though a few were much lower than 10 and a few much higher than 25. It is stated that, in spite of its evergreen habit, such variation is to be expected in a plant which is so freely branched and has so wide differences in the development of its branches that they vary almost from abortion to great luxuriance. .

\section{RHODODENDRON PONTICUM.}

General Morphology. Rhododendron ponticum, L., is a native of the Caucasus, but is cultivated in the open air in England and on the Continent, and develops well under suitable soil conditions. In a sandy soil the young plants will make shoots of $50 \mathrm{~cm}$. in length during one season, but afterwards growth is slower, and older bushes rarely make annual shoots above

1 J. B. Farmer: on the Quantitative Differences in the water-conductivity of the Wood in Trees and Shrubs, Parts I and II. Proc. Rog. Soc., B., vol. xc, I9I8.

Annals of Botany, Vo1.XXXIV. No. CXXXVI. October, 1920.] 


\section{Rivett. - The Anatomy of Rhododendron ponticum, L., and of}

$35 \mathrm{~cm}$. in length. Though often described as xerophytic in character, it has been observed that they are more liable to suffer from drought than the laurel and the Aucuba, with which they are sometimes associated in decorative shrubberies. The year's growth of a shoot is very characteristic. The winter-bud is enclosed by scales which are morphologically entire foliage leaves reduced in size: in the spring the internodes between the scales elongate considerably and the scales themselves enlarge slightly, so that they assume a form transitional between scales and true foliage leaves. They are rather delicate in texture and fall off after a short time, leaving a narrow scar, which half encircles the stem. In the early part of the summer the true, persistent foliage leaves are developed. They are often very large, I 2 to $\mathrm{I} 5 \mathrm{~cm}$. in length, and xerophytic in character. The petioles are thick and terete, leaving a circular scar where the leaves fall. They are not separated by well-marked internodes, but are crowded together in a rosette-like form. The length of the internodes is short but extremely irregular. The position of the leaves in the full-grown shoots is not affected by the light, so that the shoots retain their radial form, but there is a certain two-sidedness apparent, due to the greater growth of the leaves on the abaxial side of the axillary shoots, and on that side of the leading shoots away from the centre of the bush. The shoots are not fully matured at the end of the first season's growth, being softer and more flexible than they become later. In the axils of the lowest deciduous transitional leaves, buds are rarely developed, though they may appear in the upper ones. In the axils of the foliage leaves are large protected buds, which may remain dormant some time before they develop. The larger buds are on the abaxial side of the shoots. When the shoot terminates in a flower-bud, all the large axillary buds, some of which may remain dormant in a vegetative shoot, develop into an apparent whorl of lateral branches. These grow about $25 \mathrm{~cm}$. in length in their first season and may terminate either vegetatively or in a flower-bud. In the former case the shoot continues its growth monopodially for the next season with a possible whorl of smaller laterals immediately below it.

Material. For this investigation the material consisted of mature shoots of one season's growth. These were in groups as they had been borne on the previous year's shoot, which was cut from the shrub near its apex. The groups are lettered and figured in Diagram I. The A group consisted of A I, a main stem borne monopodically, and A 2, A $3, \mathrm{~A}_{4}$, all lateral shoots. In the $\mathrm{B}$ group, $\mathrm{B} I$ is monopodial, $\mathrm{B}_{2}$ and $\mathrm{B}_{3}$ axillary. In the $\mathrm{C}$ and $\mathrm{D}$ groups, $\mathrm{C} I$ and $\mathrm{D} I$ are monopodial and the others axillary. In the E group there is no leading monopodial shoot, as the terminal bud had either been replaced by a flower or had aborted, but there are five axillary shoots, $\mathrm{E}_{2}$ to $\mathrm{E} 6$, of which $\mathrm{E}_{2}$ assumes the form of a leading shoot. The groups were cut early in February 1919. The persistent leaves 
were removed and lengths of $\mathrm{I}_{5} \mathrm{~cm}$. were cut from each shoot and the specific conductivity registered experimentally. Subsequently the lengths were wired together and preserved in 70 per cent. alcohol.

In February the shoots are in their winter condition, showing the lower leafless part, marked with the scars of the fallen scale-leaves and a short RHODODENDRON

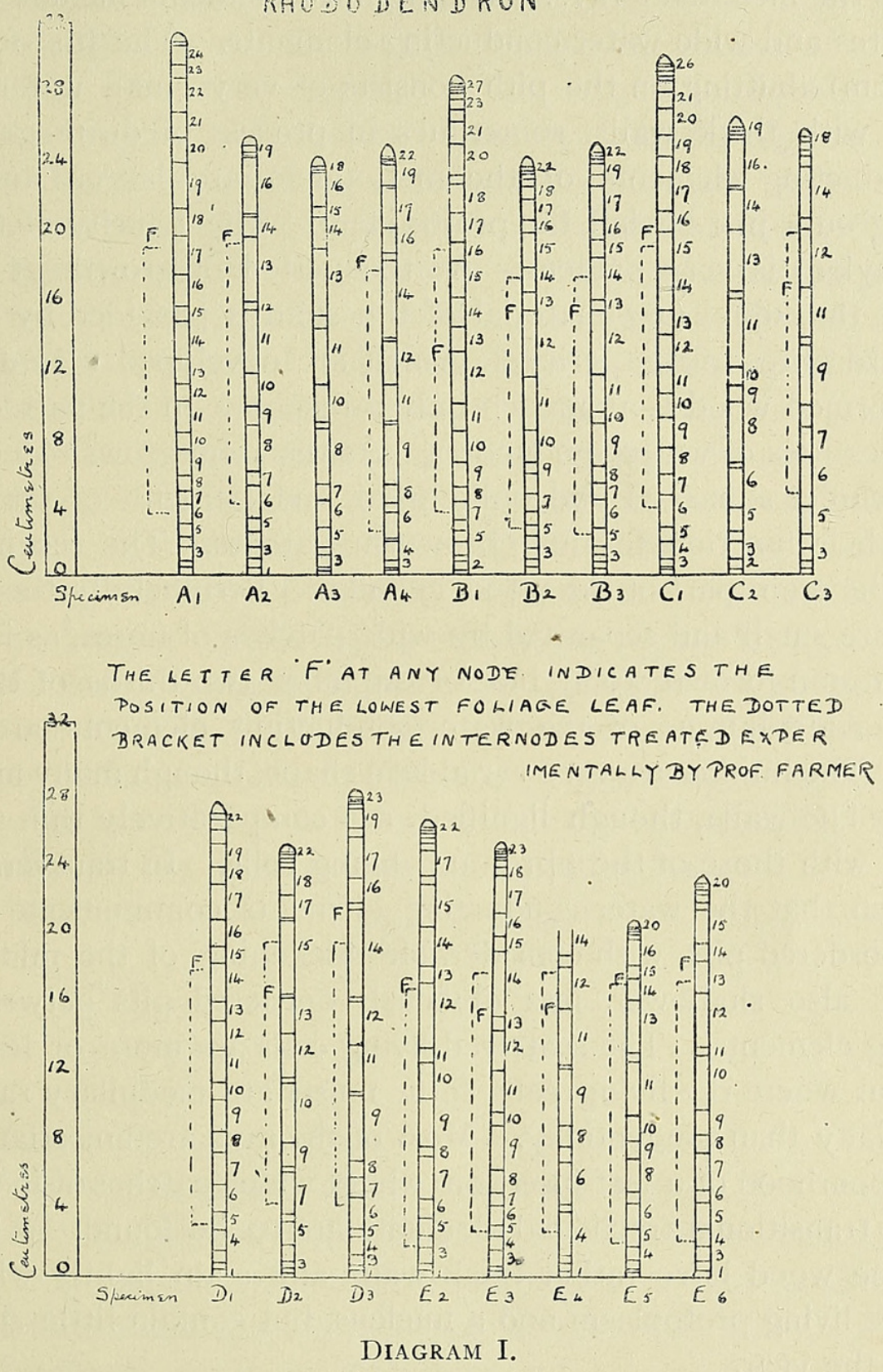

upper leafy part terminated by a dormant bud. In the axils of the foliage leaves the buds which are to produce next year's lateral branches are large and well developed. In general the shoots are between 20 and $30 \mathrm{~cm}$. long, the longest in each group being the leading monopodial shoot. The details of each can be ascertained at a glance from Diagram I.

General Anatomy. In transverse section the stem shows narrow bark and cortex, a zone of wood which is wide at the base of the stem and 
narrows upwards, and a wide pith which increases relatively towards the apex. It is hard and firm at the base, but becomes soft and flexible in the leafy region.

The wood, in transverse section, is seen to consist of dead lignified elements, interspersed with living cells, and divided radially into narrow sectors by the medullary rays. The lignified elements include small thickwalled fibres and wide water-conducting elements. The first-formed wood (protoxylem) abutting on the pith consists of very small water-conducting elements, with thick walls, sometimes in process of disintegration. The water-conducting elements of the metaxylem are larger and occur in irregular groups just behind the protoxylem. The paucity of fibres in the primary xylem is very evident. At the period of growth at which it is functional, the supporting material of the stem is provided by a peripheral ring of hard fibres in the pericycie which are developed very early. Thus the first-formed wood is almost entirely a response on the part of the plant to the necessities of water-conduction. As the stem grows older, the protoxylem becomes squashed and obliterated, and elements of the metaxylem also lose their function, forming brownish patches. The secondary xylem occupies the main part of the wood cylinder. Peripherally the conducting elements are small and separated by wide patches of fibres, as is characteristic of autumn-formed wood, but for the inner two-thirds of the wood the numerous wide lumina of the water-conducting elements are very conspicuous. The lumina are very variable in shape, though many are elongated radially. The walls, though lignified, are comparatively thin and delicate, compared with those of the fibres and living cells. In transverse section it can be seen that the water-conducting elements communicate with living cells by bordered pits, with considerable thickening of the middle lamella. There are also shallower, less obviously bordered pits between adjacent conducting elements. The scattered living cells are more or less square in section, but where the living cells form uniseriate medullary rays they are wider radially than tangentially. Most of the rays are uniseriate, except in the neighbourhood of a leaf-insertion, where wider patches of living cells and numerous transitional tracheidal elements are to be found. All the living cells in the wood have rather thick walls and stain lightly with safranin. They have living protoplasm and a nucleus, but contain little starch at this season of the year.

In longitudinal section the water-conducting elements of the protoxylem are found to be elongated vessels with spiral thickenings. They reach a length of $\frac{1}{4} \mathrm{~cm}$., as can be more easily seen from macerated material. The segments forming the vessel are joined end to end without obvious remains of cross-walls, the perforations being large and entire. These elements of the protoxylem contrast strongly with the water-conducting elements of the secondary xylem, which are made up of segments about 
fifteen times as long as broad, with their end-walls lying obliquely in the radial plane, inclined at an angle of about $30^{\circ}$ to the longitudinal axis. The lateral walls show bordered pits when they are in contact with living cells and are strengthened by reticulate thickenings. The end-walls, which appear like bulging continuations of the lateral walls, are pierced by scalariform perforations, separated by scalariform bars which may number i7 or 18 . The segments are in open continuity by means of the perforations, and thus form true vessels. Their length cannot be determined accurately by longitudinal section, since they run through several centimetres; nor by maceration, as the segments separate very easily; but reliable data can be obtained by injection with fine Indian ink. The shoots are soaked in water and the air removed by means of a suction pump : they are cut off (under water) as close to the base as possible and their basal ends immersed in a vessel of Indian ink: this is connected with a mercury pressure tube, which on elevation above the shoot will give a pressure of an atmosphere. The Indian ink is thus forced through the stem, the pressure being continued for 24 hours. When the shoot is removed, it is sectioned from the apex downwards, at intervals of $\mathrm{I} \mathrm{cm}$. The greatest height from the base at which the Indian ink is found in the wood indicates the length of the longest vessel. This maximum figure is indicative of the vessel-length, since the vessels injected do not show a continuous core of Indian ink, but a series of short interrupted columns, and many of those which appear to be empty in the basal region are found to be injected in the higher levels. The vessel-length shows considerable diversity in different shoots, as can be seen from the following table:

\begin{tabular}{|c|c|c|}
\hline & $\begin{array}{l}\text { Distance of Section } \\
\text { from base in } \mathrm{cm} \text {. }\end{array}$ & $\begin{array}{c}\text { Number of Vessels } \\
\text { injected. }\end{array}$ \\
\hline Shoot & I I & 5 \\
\hline " & I I & 5 \\
\hline ", & 6 & 3 \\
\hline " & 9 & 3 \\
\hline$"$ & I6 & 3 \\
\hline " & I 2 & 3 \\
\hline
\end{tabular}

Thus the lowest figure $(6 \mathrm{~cm}$.$) and the highest (16 \mathrm{~cm}$.) represent lengths of stem in different shoots in which the vessels are continuous.

These long vessels with their short segments and small scalariform perforations form the characteristic tissue of the wood, and no unperforated tracheides are found associated with them in the wood cylinder. But these latter elements are numerous at the periphery of the wood in the neighbourhood of the insertion of the petioles : they are of varying form, often short, wide, and irregular, and serve to connect the petiolar wood strands with the long vessels of the wood cylinder.

The two-sidedness of the shoot, which is evident in the growth of the leaves, also shows itself in the anatomy. The cylinder of wood is widest on the abaxial and narrowest on the adaxial side of the stem. On the abaxial 
side there is also a higher proportion of vessels to fibres than there is on the narrow side.

\section{Ilex Aquifolium.}

General Morphology. The Holly (Ilex Aquifolium) is a fairly rapid grower, making shoots up to $30 \mathrm{~cm}$. long in a single season. The year's growth is simple, such as is found in most evergreen trees. There is a terminal winter-bud, bearing 5 or 6 spirally arranged scales. When the young shoot elongates in the spring, the scales fall off, but two or three transitional leaves are borne between the first elongated internodes, before the true foliage leaves appear: of these, fifteen may be borne in a single season. The internodes show the usual gradations in a year's growth-i.e. the longest are in the middle and the shortest towards base and apex. The transitional scale-foliage leaves fall during the first season, leaving a narrow encircling scar similar to that of the bud-scales. The foliage leaves may persist for four or five years, but usually some of the lower ones in each year's growth fall off in their second and third year. Buds are found in the axils of the scale leaves and the foliage leaves, but it is only in the upper regions of a year's growth that they normally develop into lateral branches. The shoots are soft and immature at the end of the first season, but they harden and increase in girth in successive years. The growth from year to year is monopodial, as it is the terminal winter bud which develops at the beginning of each season.

Material. For this investigation the material consisted of straight twigs of three, four, or five years' growth, cut in July 1919. The twigs are figured and lettered in Diagram II. From this it can be seen that the twig $\mathrm{F}$, of total length $52 \mathrm{~cm}$., consisted of three successive annual shootsa I9I 6 shoot of 15 internodes, $22 \mathrm{~cm}$. long: a I9I 7 shoot of 13 internodes, $19^{\circ} 6 \mathrm{~cm}$. long: a 1918 shoot of 14 internodes, $10.4 \mathrm{~cm}$. long-and an abortive I9I9 shoot. Thus the twig exhibits four annual rings at the base, three in the middle, and two at the upper end. The scars of the winter-bud scales are taken as indicating nodes and are reckoned in the total internodes numbered from base to apex. The shoot $\mathrm{G}$, of total length $5^{2} \mathrm{~cm}$., consisted of four successive annual shoots: the oldest, dating from 19I5, shows five annual rings: the topmost, dating from 19I8, shows two annual rings, there being again no one-year-old shoot, owing to abortion or accident in the early spring of 1919 . The shoot $\mathrm{H}$, of total length $63 \mathrm{~cm}$., shows four successive annual shoots, including the uppermost still active in July 1919. The shoot $\mathrm{K}$, showing five successive years' growth, is the longest and stoutest of the set and reaches a length of $77 \mathrm{~cm}$. The shoot $\mathrm{L}$ shows great length, $5^{8} \mathrm{~cm}$.- considering that it is made up of three annual shoots only. The internodes are particularly long, straight, and well developed. The shoot M, of four years' growth, reaches a length of $73 \mathrm{~cm}$. 
Further details of these shoots can be seen at a glance from Diagram II, where they are drawn to scale to show the spacing of the nodes and internodes. It should be particularly noticed that the shoots $F$ and $G$ are truncated.

General Anatomy.

In the transverse section of the stem there is a narrow bark and cortex, except in the first year's growth, where it may occupy about a third of the diameter. The pith appears relatively small at the base, but remains much the same actual size throughout a considerable length, being little affected by the tapering of the stem, so that it appears relatively large at the apex. The wood is very hard and consists of dead, lignified elements, separated radially by narrow medullary rays, which vary from one to four cells in thickness. The protoxylem elements are few in number and of narrow diameter. They are all water-conducting elements, the supporting tissue of the very young shoot being provided by a ring of fibres in the pericycle. Except at the apex of the one-year-old

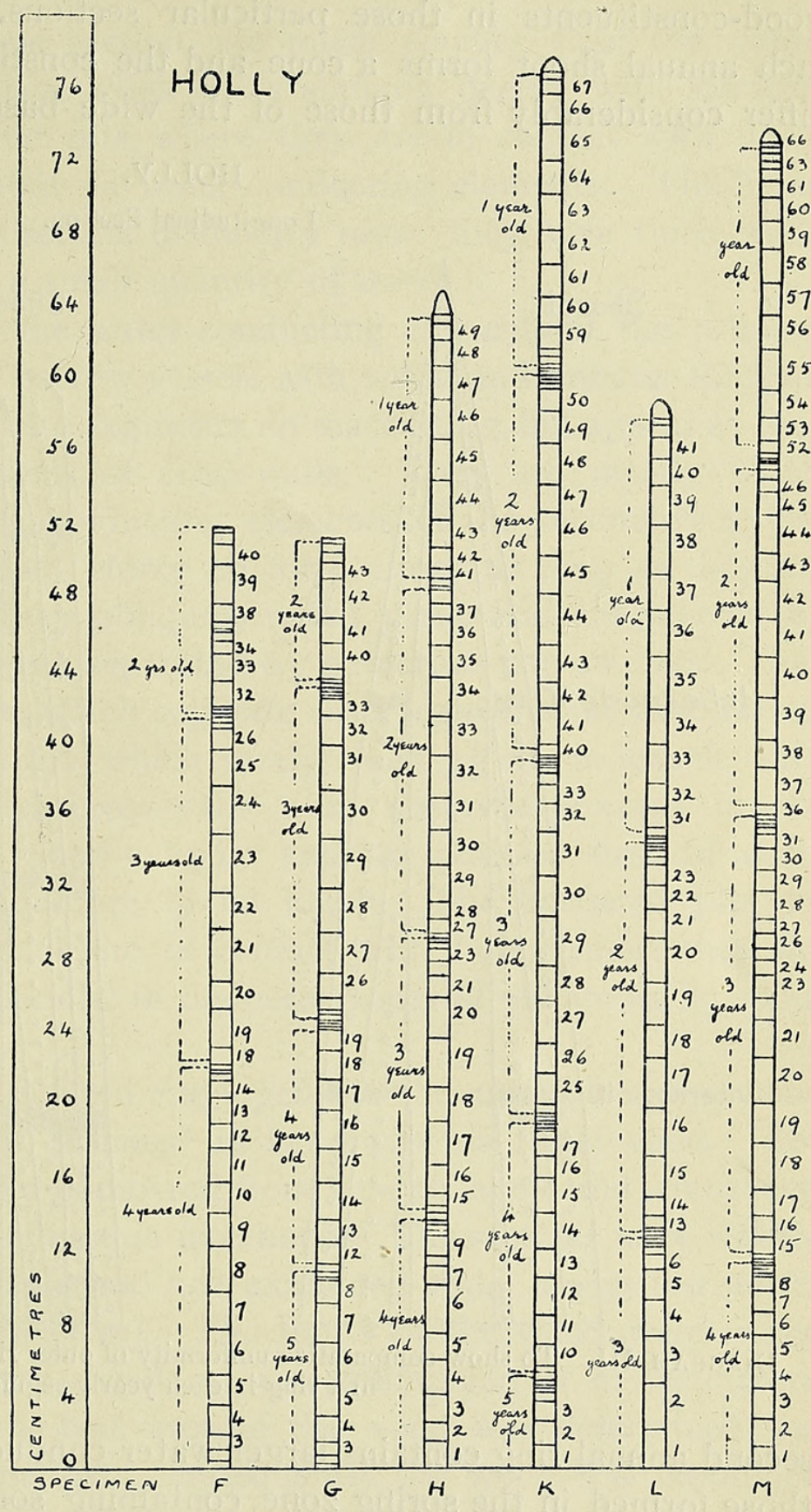

DIAGRAM II. shoots, the protoxylem elements are inconspicuous, being obscured by disintegration products due to pressure. In general the spring wood of the first year contains numerous large water-conducting elements immediately outside the primary xylem, while the autumn wood consists largely of fibres; but just below the junction of each petiole, the first-year wood contains a welldefined radial group of very numerous small water-conducting elements, 


\section{Rivett.-The Anatomy of Rhododendron ponticum, L., and of}

which exert a modifying influence on the analysis of the wood in sectors-that is to say, a sector through one of these groups must be combined with sectors on different radii, in order to obtain a true average view of the wood-constituents in those particular sections. The first-year wood in each annual shoot forms a cone, and the constituents of the narrow apex differ considerably from those of the wide base (see Diagram III). The

HOLLY.

Longitudinal Section.

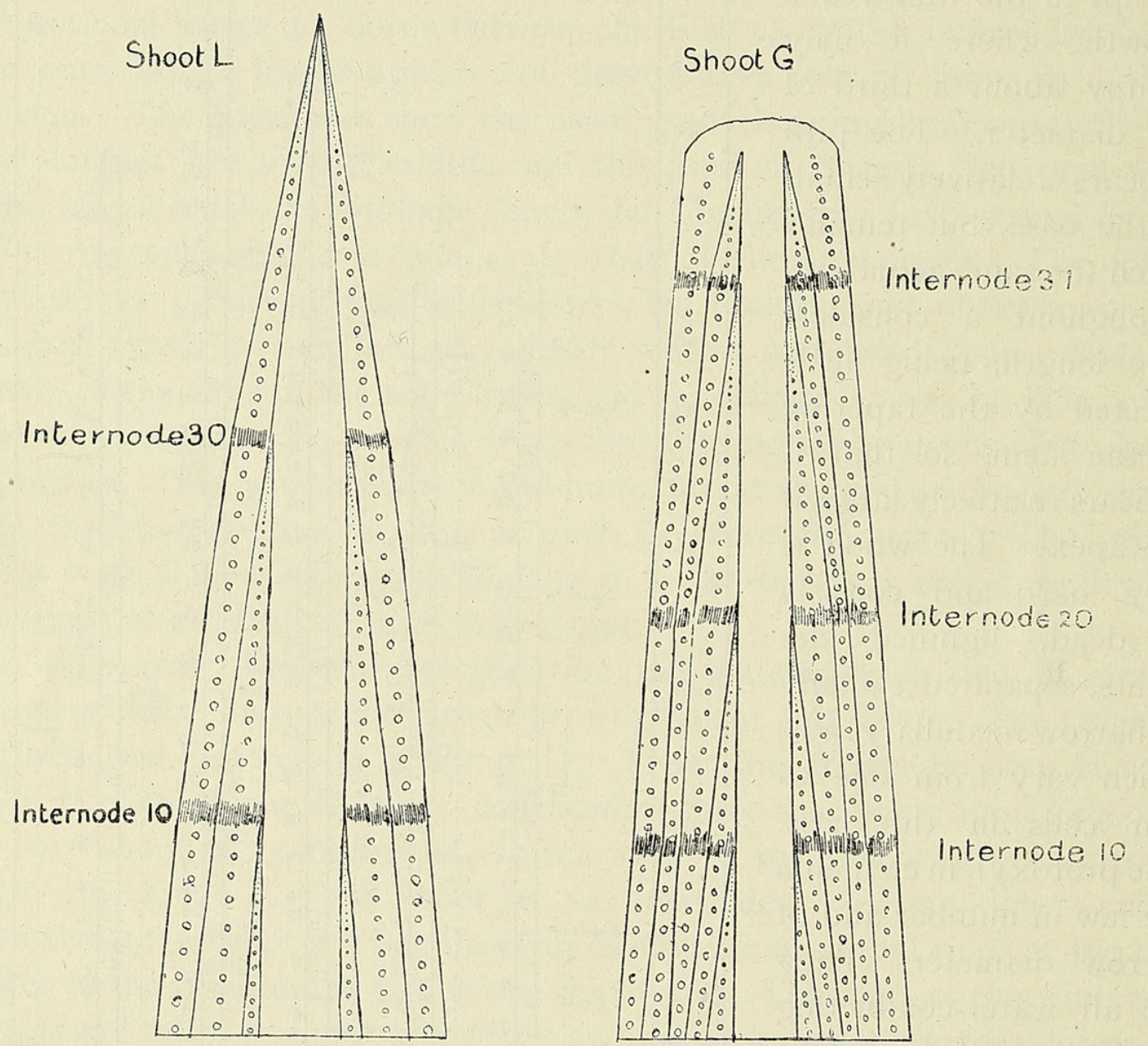

DiAgram III. To show comparative uniformity of outer rings of wood as compared with the first ring in each yearly segment.

second annual ring contains larger water-conducting elements than the first, those formed in the spring zone containing some of the widest individual elements to be seen. They are arranged more or less in radial rows or groups, with intervening radial patches of fibres. The third-, fourth-, and fifth-year woods are all very similar on a general inspection of transverse sections, showing wide water-conducting elements and patches of fibres. Owing to their similarity at different levels in the stem, they modify the general average analysis of old shoots to a considerable extent, and partially eliminate the variations noticed in the cone of the first-year wood. In July, when the wood was cut, cambial activity is still in progress and the 
outermost zone of wood contains elements not altogether differentiated. In all the conducting elements bordered pits can be seen in transverse section wherever they are in contact with living cells or with other waterconducting elements.

The fibres, in transverse section, are much smaller than the waterconducting elements, and have thick walls staining deeply with safranin. They show slightly bordered pits, where they are in contact with living cells, but not where they abut on water-conducting elements. The living cells are largest in the multiseriate medullary rays : they have thick walls, protoplasmic contents, and a small quantity of starch.

In longitudinal section the water-conducting elements of the primary xylem are found to be long narrow vessels with spiral and annular thickenings, which do not separate into segments on macerating, but appear as long tubes without obvious remains of cross-walls. They are mostly under a centimetre in length. The conducting elements of the secondary xylem are elongated segments, about thirty to forty times as long as they are broad. The end-walls lie in an obliquely radial plane and are pierced by narrow, scalariform perforations, separated by numerous narrow bars. Thus they form continuous vessels, which separate into segments on macerating, but on injection appear as tubes which rarely reach $3 \frac{1}{2} \mathrm{~cm}$. in length. No segments with unperforated cross-walls were observed, except in the junction tissue between the wood cylinder and the petiolar strands, where numerous irregular tracheides are to be found. The bordered pits are abundant wherever the vessels are in contact with living cells : they are frequently accompanied, especially in the outer zones of old stems, by spiral and reticulate thickenings.

Method. The general method employed for the analysis of the wood is that put forward by Miss Holmes ${ }^{1}$ in her paper on hazel-wood. The internodes of each shoot were numbered from base to apex and transverse sections made in the midst of certain internodes. The sections were stained with haematoxylin and safranin and first examined under a very low power of the microscope (2-inch objective). The limits of the wood were traced on paper by means of a camera lucida at a magnification of $2 \mathrm{I}$ diameters. By means of a planimeter the true area of the wood was determined and calculated in square millimetres. Subsequently the wood was examined under a high power of the microscope (one-sixth inch objective), and again, by means of a camera lucida, an exact representation of the cavities of the water-conducting elements in a sector of known area was drawn on millimetre-squared paper. From this drawing the total area of all the cavities was obtained by counting the square millimetres which they contained. The number of elements in the known sector was also counted. Thus the

1 M. G. Holmes : A Study in the Anatomy of Hazel-Wood with Reference to Conductivity of Water. Ann. Bot., vol. xxxii, I9I 8 . 


\section{Rivett.-The Anatomy of Rhododendron ponticum, L., and of}

proportion existing between the area of the cavities and the area of the known sector of wood was obtained. By dividing the total area of cavities by the square of the linear magnification and combining this with the true area of wood, the total area of the cavities in a complete transverse section was easily calculated. Further data which were calculated were the average area of the cavities and the number of cavities per square millimetre.

Accuracy. Owing to the comparative smallness of the field under a high power of the microscope, only a small sector of the wood can be examined at once. Neither in Rhododendron ponticum nor in holly is any such sector typical of a whole transverse section. The variability of the wood on different radii is due in Rhododendron ponticum to (i) the twosidedness of the stem, (ii) the existence of tracts of living cells associated with the insertion of the petioles; in holly the variability is due to the living cells and small vascular elements associated with the insertion of the petioles. Theoretically, perfect accuracy can only be obtained by ascertaining the cross-area of every water-conducting element in every section; the laboriousness of this being evident, it was found that the approximation arrived at by combining three or five sectors gave satisfactory results.

Results. The results given by the above-described drawings and calculations are represented by a series of graphs. In all cases the internodes numbered from base to apex are plotted along the horizontal line, an equal interval $(0.2 \mathrm{~cm}$.) being taken for each internode, irrespective of its length. A special vertical scale is chosen for each set of figures according to the following plan :
A. Total wood area in sq. $\mathrm{mm}$.
I $\mathrm{cm}$. represents $5 \mathrm{sq} . \mathrm{mm}$.
B. Total cavity area in sq. $\mathrm{mm}$.
I $\mathrm{cm}$. represents I sq. $\mathrm{mm}$.
C. Percentage of wood occupied by cavities .
I $\mathrm{cm}$. represents 2 per cent.
D. Average area of cavities in sq. $\mu$
I cm. represents 40 sq. $\mu$.
E. Number of cavities per sq. mm.
I cm. represents 200 .

By plotting points for each set of figures against the chosen internodes, a series of curves are obtained which show how they vary at different levels of the stem. The members of the series are indicated by the letters assigned to the plan of vertical scales put out above. The curves for the different shoots of Rhododendron ponticum are illustrated in Diagrams IV to XIII : the curves for the shoots of holly in Diagrams XIV to XVII.

Curve A (total area of wood in sq. $\mathrm{mm}$.). In general this is a smooth curve descending from base to apex. The descent is due to the general tapering of the stem and the increase in the relative area of the pith in the higher levels. In Rhododendron ponticum the descent is generally more rapid towards the base than in the middle and apical regions, but this is not generally apparent in the holly. Of the rhododendron shoots $\mathrm{BI}$ is the most massive, showing a wood-area of $32.2 \mathrm{sq} . \mathrm{mm}$. at the base; in general the leading shoots are thicker than the lateral: in some cases 
$\left(\mathrm{C}_{3}, \mathrm{C}_{\mathrm{I}}, \mathrm{A}_{\mathrm{I}}\right)$ there is a flattening of the curve at the beginning of the leafy region of the stem, where the general tapering is influenced by the close succession of the petioles and the shortness of the internodes. The shoot $\mathrm{A}_{3}$ has the lowest figure for wood-area $(8 \cdot 2 \mathrm{sq} . \mathrm{mm}$. at the base). Among the holly twigs it should be noticed that in Shoot $\mathrm{L}$ the wood-area reaches 24.6 sq. $\mathrm{mm}$. at the base of the three-year-old shoot. In Shoot H it is only $14.9 \mathrm{sq} . \mathrm{mm}$. at the base of the four-year-old shoot.

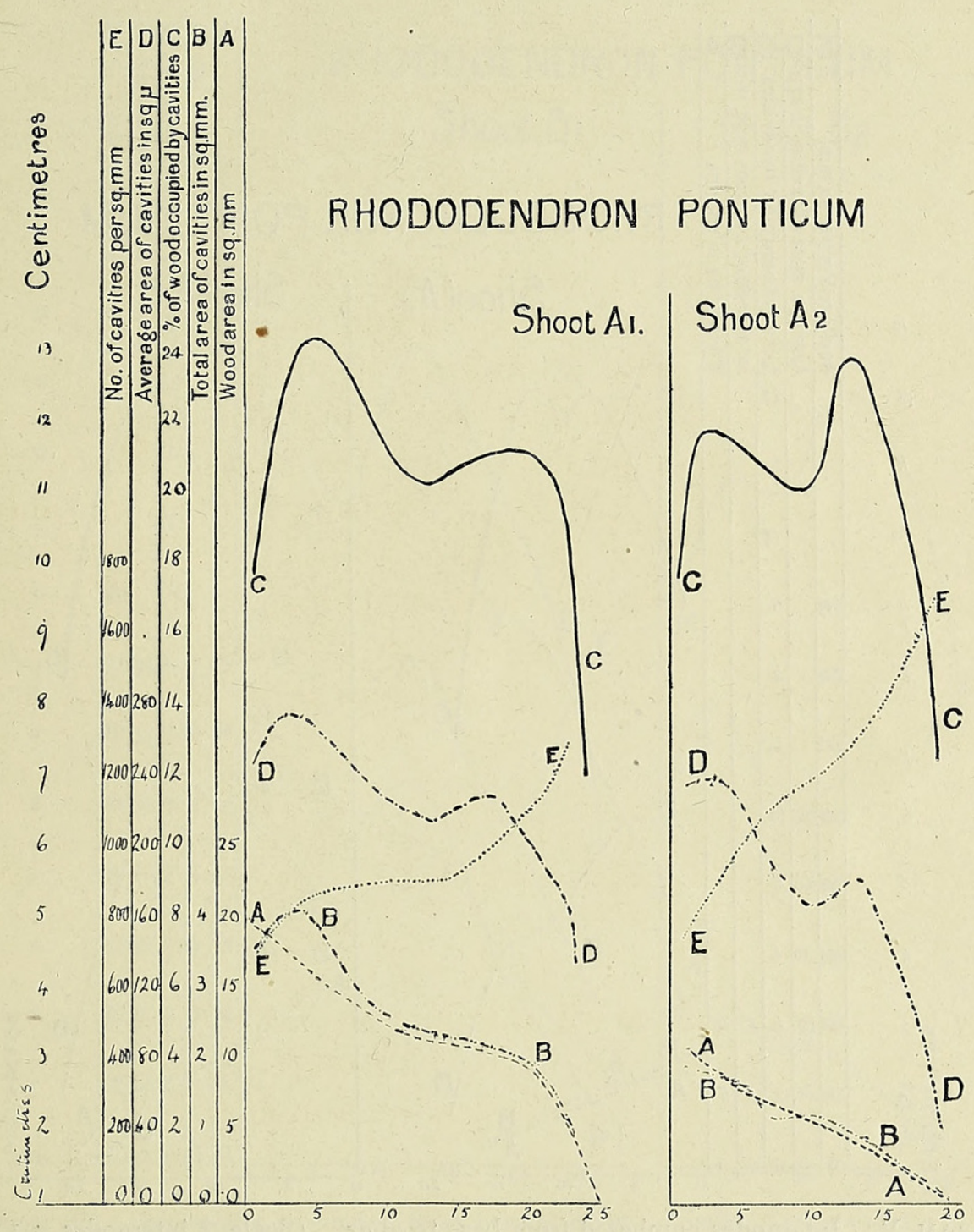

Diagram IV. Internodes numbered from base to apex. (Scale, 5 internodes $=\mathbf{I ~ c m}$.).

Curve B (total cavity area in sq. mm.). This curve gives (as far as is possible from a consideration of transverse sections) a measure of the absolute conductivity of the wood-i.e. of the volume of water which it can transmit in any known period of time. Its direction is associated with that of Curve A, consequently there is a general descent from base to apex. There are peculiarities in the curves for the rhododendron shoots, different from those seen in holly. In the shoots of Rhododendron ponticum, in 
which the mass of supporting fibres is limited to the extreme base, and in which there is a sudden increase of vessels in the first elongated internodes, the curve tends to rise slightly at first, because the increase in the total cross-area of the vessels more than makes up for the slight decrease in area of the wood. This preliminary rise is most marked in Shoots $\mathrm{E}_{4}$, $\mathrm{E}_{2}, \mathrm{D}_{1}$, and A I. Similarly, at the beginning of the foliar region, where there is a slight increase in the size of the vessels, we may have either

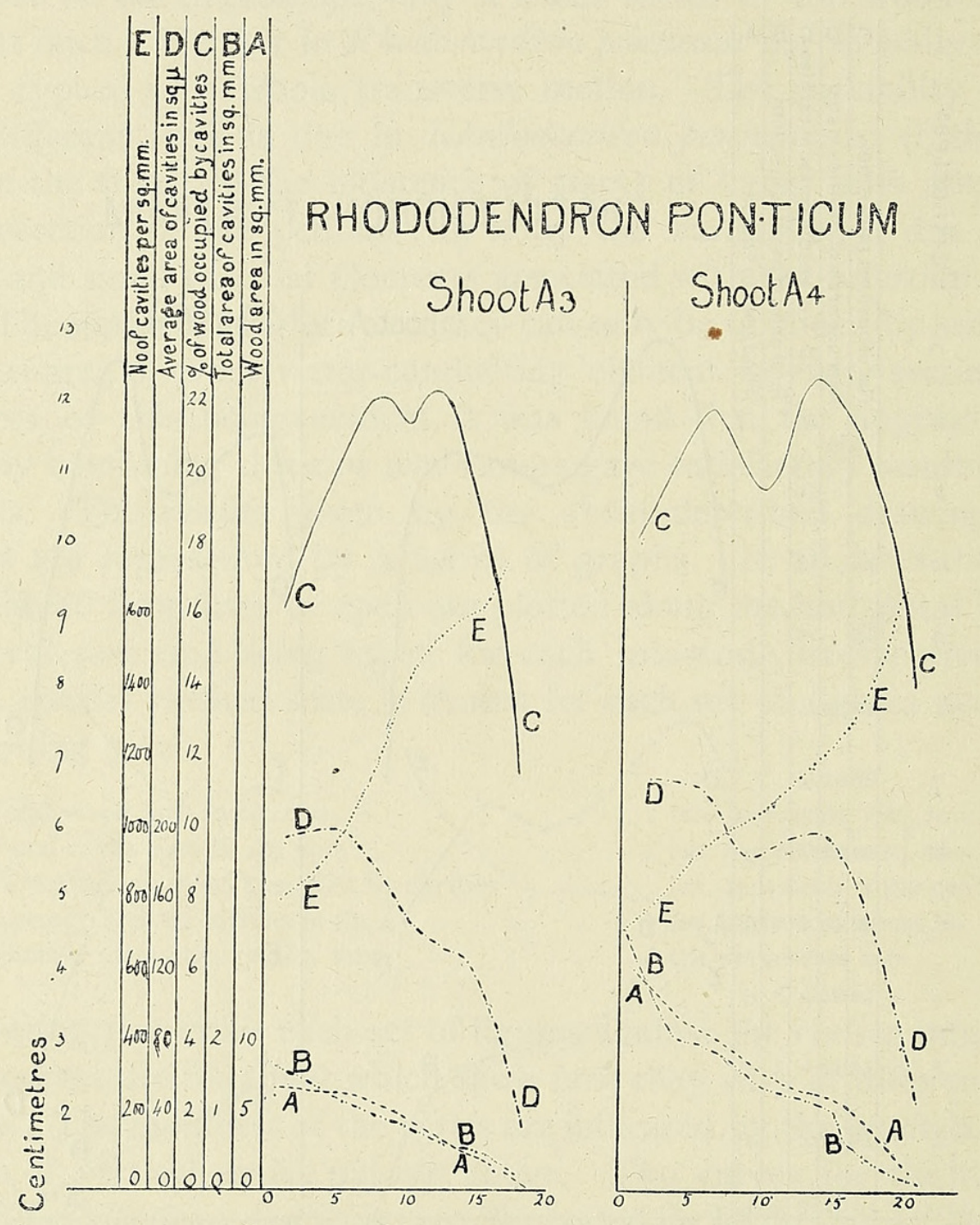

DiAgram V. Internodes numbered from base to apex. (Scale, 5 internodes $=\mathbf{I} \mathrm{cm}$.)

a flattening or slight ascent of the curve, because here the tapering of the stem is slight and any increase in the actual area of the vessels becomes noticeable in the total area in the section. The range of actual figures is from 5.9 sq. $\mathrm{mm}$. in $\mathrm{B}_{\mathrm{I}}$ to $\mathrm{I} \cdot 4$ sq. $\mathrm{mm}$. in $\mathrm{A}_{3}$. In the shoots of holly the general descent of the curve throughout the length of the twig is interrupted by more sudden descents at the yearly joints, which begin at the apex of one year and extend into the lowest internodes of the next. These sudden descents are due to a decrease in number of water-conducting 
elements at these points (see Curve E). The slight variations in the form of the curve in different shoots and different years are due to the varying number of internodes, to the rate of decrease in the wood-area, and to the changes in size and number of the water-conducting elements. In Shoot F the curve is nearly flat at the beginnings of the yearly segments and descends at their apices: it terminates nearly flat owing to the abortion of the apex. In Shoot $G$ the curve is very similar, but there is a slight

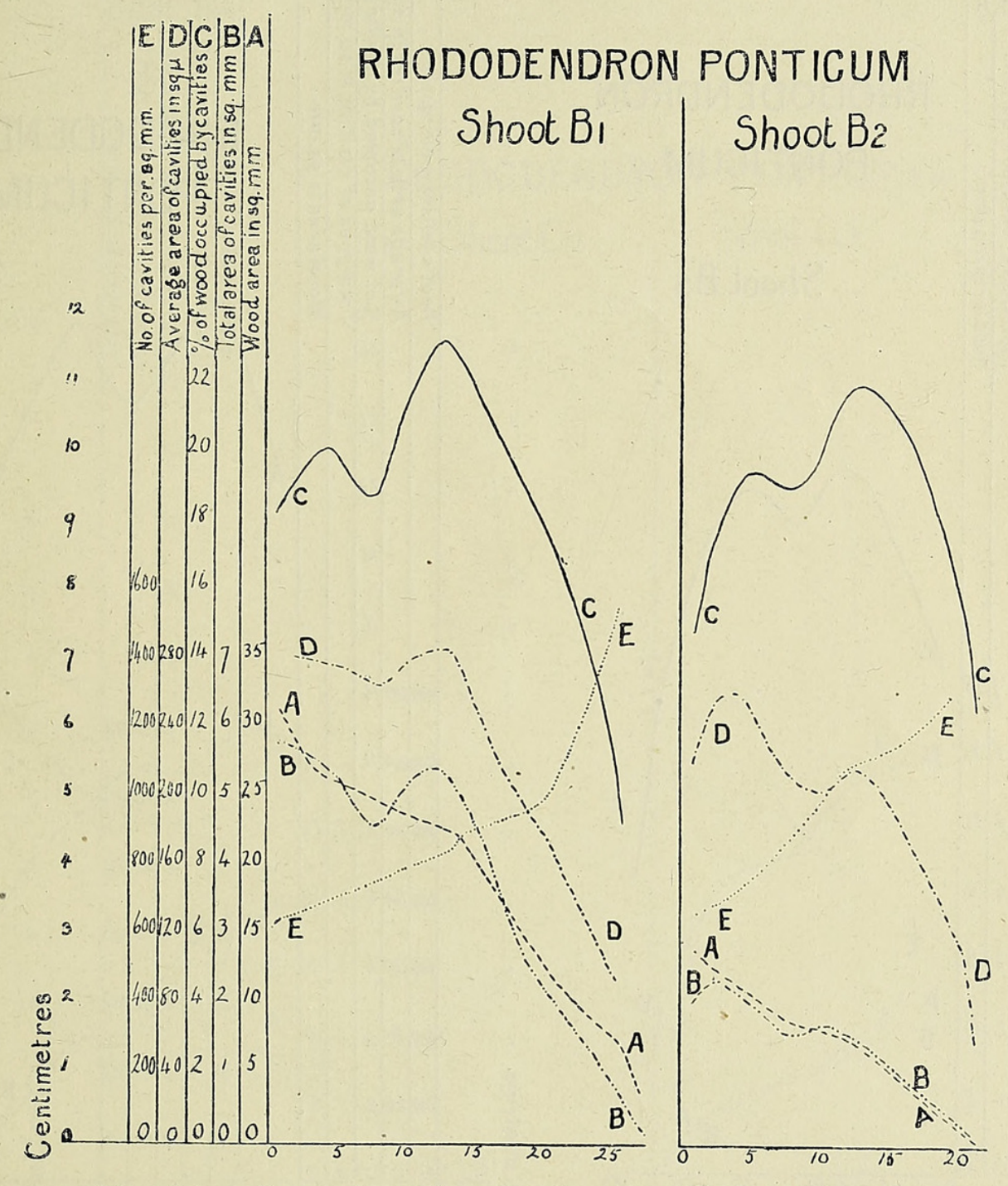

Diagram VI. Internodes numbered from base to apex. (Scale, 5 internodes $=\mathrm{I} \mathrm{cm}$. )

departure from the general descent in the middle of the three-year-old segment, due to the large number of water-conducting elements at that region. In Shoot $\mathrm{H}$ the general descent is very gradual, because the stem tapers very gently and there is no great variation in the cross-area of the water-conducting elements throughout the very long stem, but the yearly segments are well marked. In Shoot $\mathrm{K}$ the yearly segments are again well marked, and, though they are similar in form, the actual figures vary considerably. In the four-year-old segment the wood-area is decreasing 
slightly, but the more numerous water-conducting elements in its middle region causes the curve to be slightly rounded: this is even more marked in the three-year-old segment, where the wood-area decrease is slight and the water-conducting elements are very numerous in the middle region. In the two-year-old segment the wood-area decrease is again steeper, but

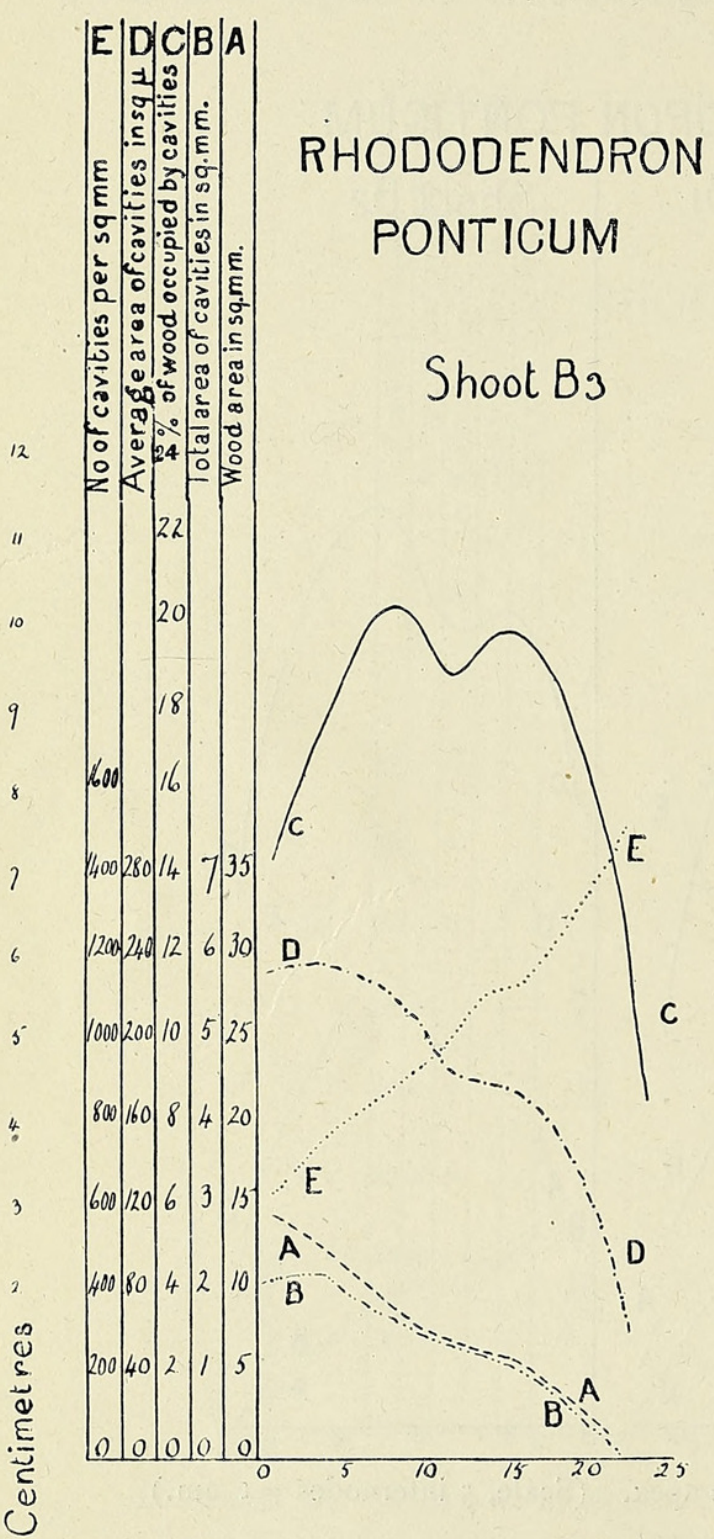

DiAgRAM VII. Internodes numbered from base to apex. (Scale, 5 internodes $=\mathrm{I} \mathrm{cm}$.)

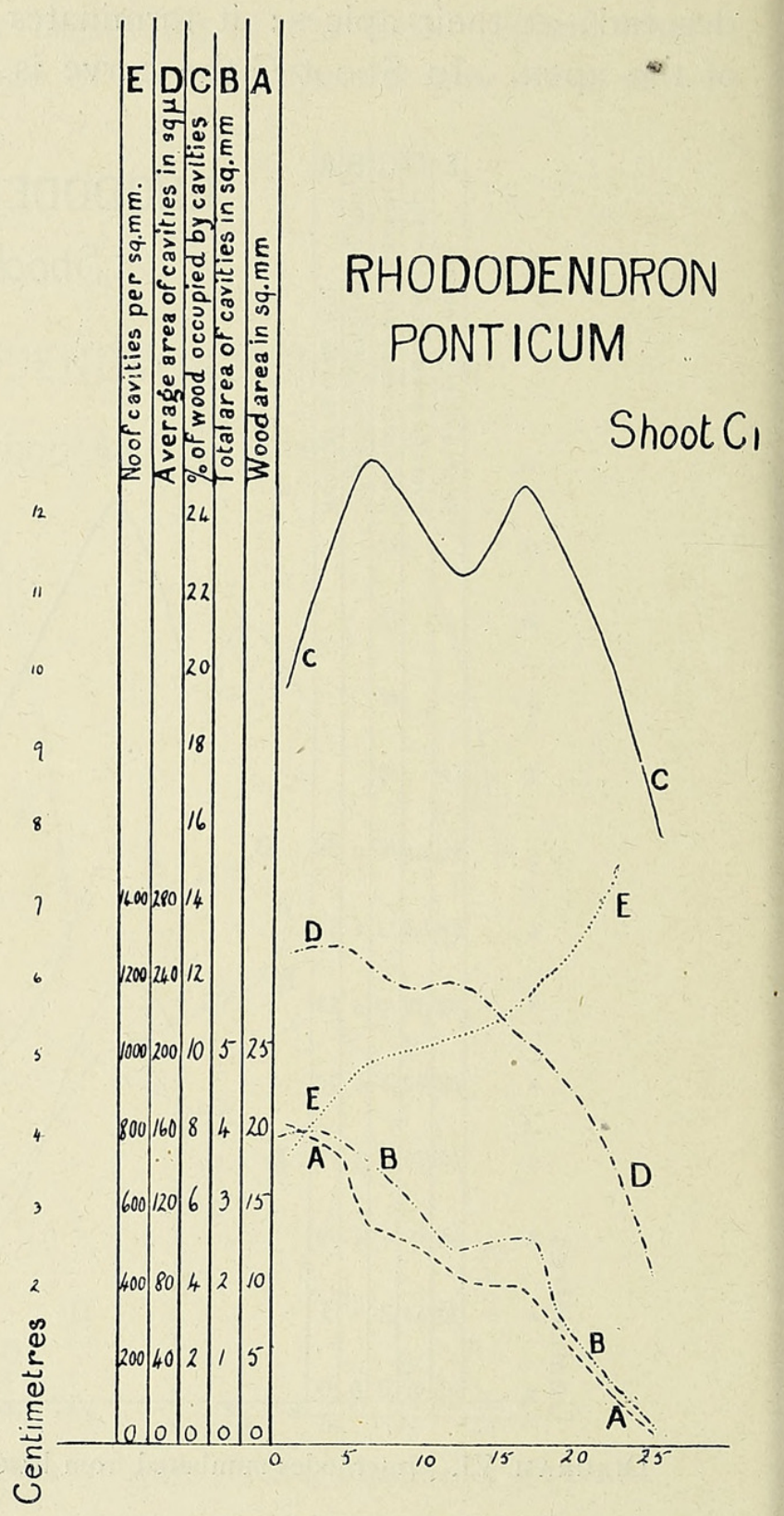

DIAGRAM VIII. Internodes numbered from base to apex. (Scale, 5 internodes $=\mathrm{I} \mathrm{cm}$.)

the change in the number of conducting elements still causes the curve to be rounded. In the one-year-old segment there is only a general decrease and no rounding of the curve, consequent on the decreasing size of the elements and the decrease in wood-area. In Shoot $\mathrm{L}$, which was a rapidly growing, well-favoured specimen, there is a marked fall of the curve at the end of the three-year-old segment, but the rest of its descent is gradual. 
Curve $C$ (percentage of the wood occupied by the cavities of waterconducting elements). This curve illustrates, as far as is possible from the consideration of transverse sections, the anatomical basis of the variations in the water-conducting powers of the wood, and thus is to be correlated with the specific conductivity-i.e. with the volume of water transmitted

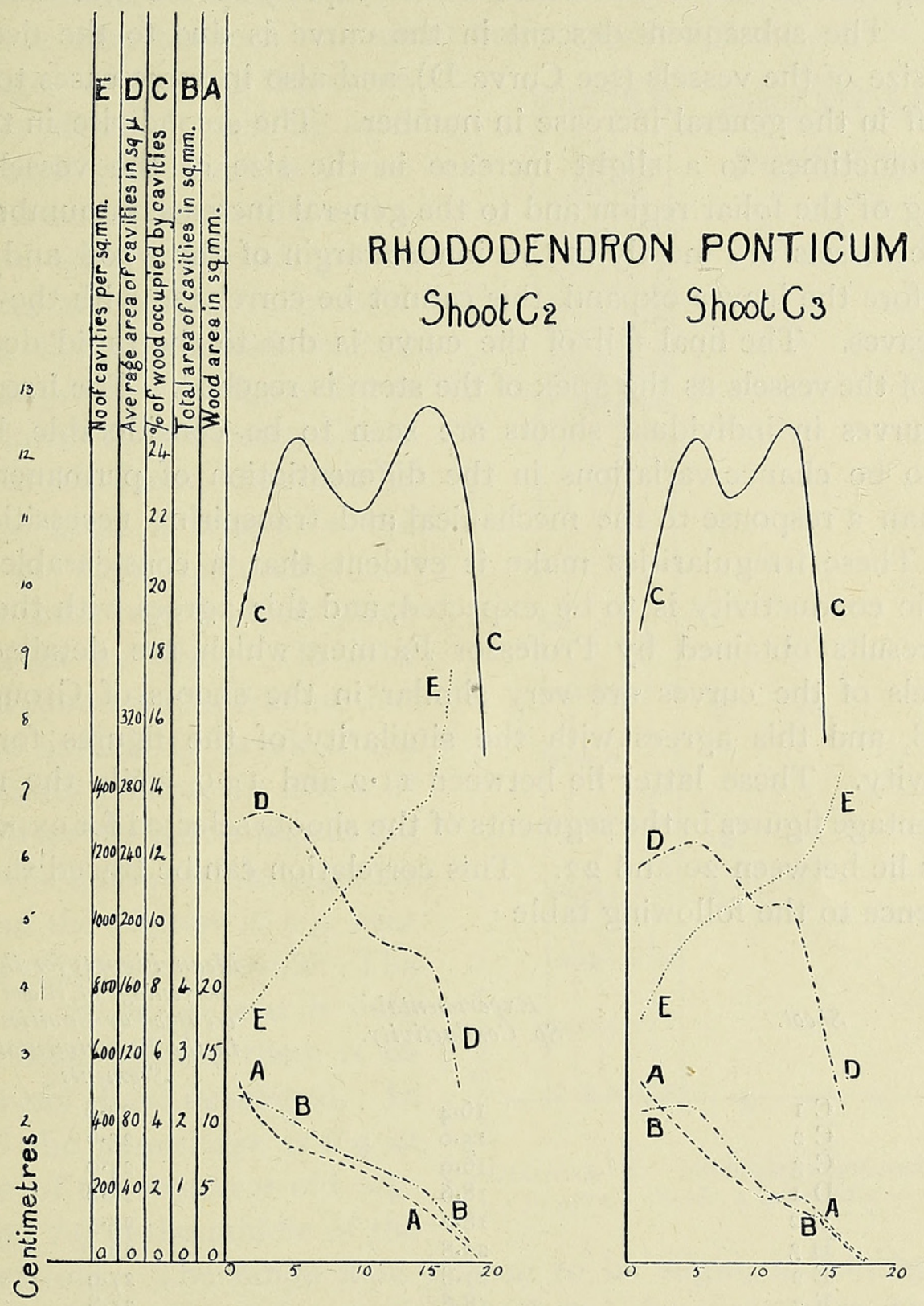

DiAgRAm IX. Internodes numbered from base to apex. (Scale, 5 internodes $=\mathbf{I ~ c m}$.)

by a length of $15 \mathrm{~cm}$. per I sq. mm. of wood as seen in transverse section. There are considerable differences in the curves exhibited by the one-yearold shoots of Rhododendron ponticum and the three- or four-year-old shoots of holly, but in general the curves rise from the base and fall away again to the apex. In rhododendron the curves may be described and explained as follows: The steep rise from the base through the lower internodes 
is succeeded by a descent below the leafy nodes, but this gives place to another ascent before the rapid fall to the apex. The first steep rise indicates a great increase in the number of vessels in the first elongated internodes (see Curve E): these supplant the fibres which act as supporting tissue, at the extreme base. They form the vascular tissue which supplies the young transitional leaves which unfold rapidly in the first warm spring weather. The subsequent descent in the curve is due to the decrease in average size of the vessels (see Curve D), and also in some cases to a slight falling off in the general increase in number. The second rise in the curve is due sometimes to a slight increase in the size of the vessels at the beginning of the foliar region and to the general increase in number, but as the large vessels are mostly at the inner margin of the wood and are laid down before the leaves expand, this cannot be correlated with the activities of the leaves. The final fall of the curve is due to the rapid decrease in the size of the vessels as the apex of the stem is reached. The irregularities of the curves in individual shoots are seen to be considerable, but they appear to be chance variations in the differentiation of permanent tissue, rather than a response to the mechanical and transpiring necessities of the leaves. These irregularities make it evident that a considerable latitude in specific conductivity is to be expected, and this agrees with the experimental results obtained by Professor Farmer, which are detailed below. The levels of the curves are very similar in the shoots of Group A and Group B, and this agrees with the similarity of the figures for specific conductivity. These latter lie between II.2 and I 3.9 , while the means of the percentage figures in the segments of the shoots selected for experimental purposes lie between 20 and 22 . This correlation can be traced throughout by reference to the following table:

$\begin{array}{cc}\text { Shoot. } & \begin{array}{c}\text { Experimental } \\ \text { Sp. Conductivity. }\end{array} \\ \text { C I } & \\ \text { C 2 } & 16.4 \\ \text { C 3 } & 15 \cdot 0 \\ \text { D I } & 16.9 \\ \text { D 2 } & 18.6 \\ \text { D 3 } & 18.2 \\ \text { E 2 } & 20.8 \\ \text { E 3 } & 21.8 \\ \text { E 4 } & 18.6 \\ \text { E 5 } & 20.7 \\ \text { E 6 } & 19.4 \\ & 15.5\end{array}$

Mean Figures for the
percentage of Wood
occupied by Cavities
in the Experimental
Segments.
24.0
23.6
24.0
25.8
25.5
26.5
27.9
25.8
27.2
26.0
23.6

In the holly shoots the $\mathrm{C}$ curves show a general rise from the base to a maximum somewhere near the apex of either the two-year-old or cneyear-old segments, and then fall away to the terminal bud, but, as in Curve B, the general trend is obscured by sudden interruptions at the yearly joints. The position of the maximum indicates that the first-and second-year wood 


\section{Ilex Aquifolium, L., in Reference to Specific Conductivity. 54 I}

is richer in vessels than the outer rings. If a mean line is drawn touching the maxima of successive yearly segments, it will be found to have a general inclination upwards to the middle of the two-year-old or one-year old segment. The whole range of the line lies between $7 \cdot 5$ and 10.5 , and the inclination becomes less and less in the older segments. This agrees with Professor Farmer's experimental results for the specific conductivity, which he found to vary between very small limits $(9 \pm 2)$ without any divergences due to age. Following the curve in greater detail, it will be seen that in each year there is a rise from the base to the middle and a fall to the apex. At each yearly joint there are several internodes (between the winter-bud scales) where the percentage figure is relatively low. In discussing Curve $\mathrm{E}$, it will be found that this is due to a great decrease in the number of water-conducting elements at these regions, their place being taken by fibres. It is a matter of common observation that twigs are hardest to break or cut at the yearly joints. In Shoot F the figure for the percentage at the base of the four-year-old segment is $7 \cdot 1$ and the highest is $9 \cdot 5$, near the apex of the two-year-old. The descent at the upper end is only to 5 per cent. because there is no one-year-old shoot developed. In Shoot $\mathrm{G}$ the percentage is 6.9 at the base of the five-year-old segment and 7.9 in the middle of the

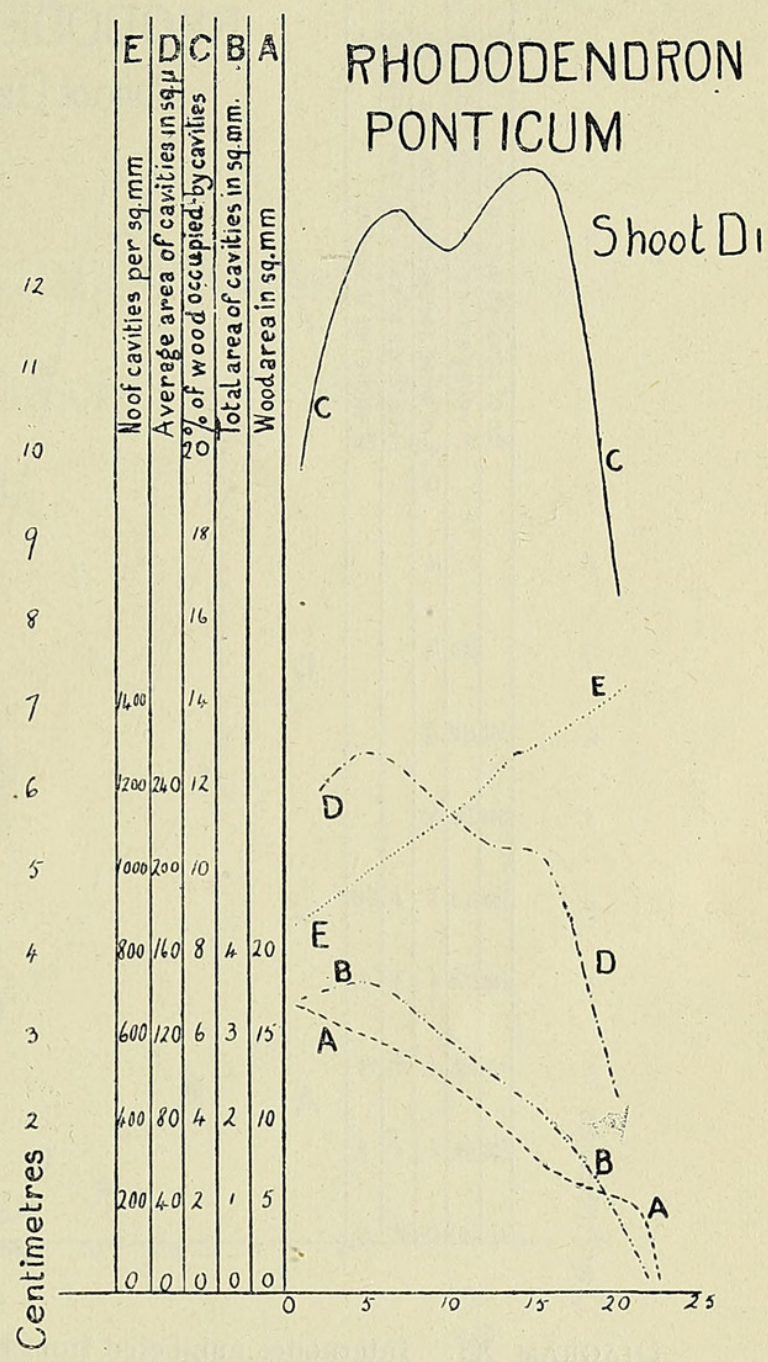

DIAGRAM $\mathrm{X}$. Internodes numbered from base to apex. (Scale, 5 internodes $=\mathrm{I} \mathrm{cm}$.) three-year-old. The range here is seen to be slight, indicating that the percentage figure is not materially affected by age, once maturity is established. In Shoot $H$ the yearly phases are very clearly marked and also the closeness between the maxima and minima in different years. The total range is from $6 \cdot 0$ at the base of the three-year-old segment to $10 \cdot 0$ in the middle of the two-year-old. Shoot K, the longest and stoutest of the set, is the richest in conducting tissue : even at the yearly joints, the percentage does not fall below $6 \cdot 0$ and it rises to II $\cdot 3$ in the middle of the three-year-old segment. This is due to large numbers of vessels and not 
to variations in their cross-area. In Shoot $\mathrm{L}$, which has very long internodes and appears rapidly grown, the range between the maxima is very slight$7 \cdot 9,8 \cdot 1$, and $8 \cdot 5$ being the figures found in successive yearly segments : the readings at the joints are 6.8 and 7.4 and the rich conducting-tissue is maintained until the last two internodes. In Shoot $M$ the figures are normal in the lower yearly segments, but the one-year-old shoot was very

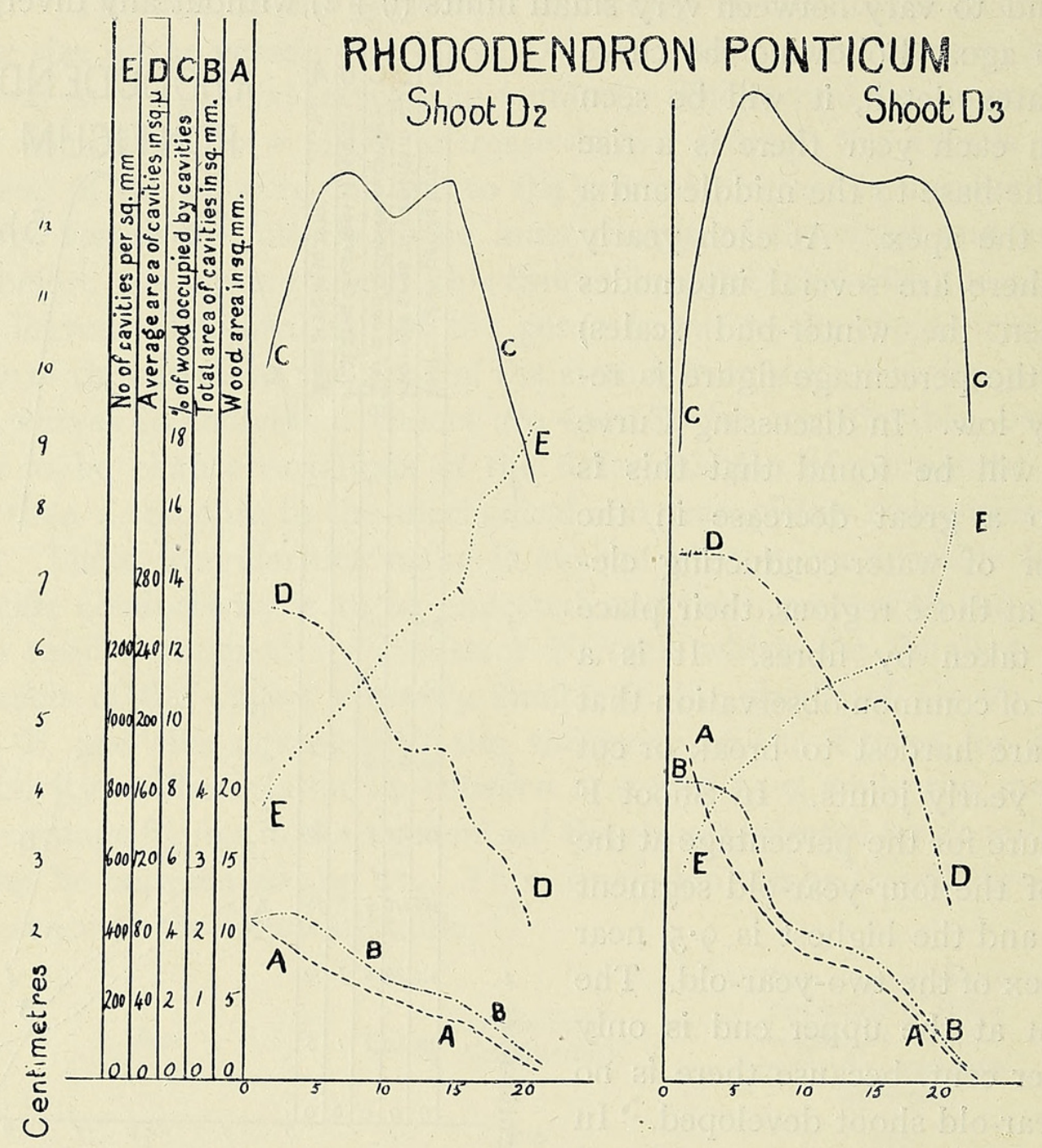

DiAgram XI. Internodes numbered from base to apex. $\quad($ Scale, 5 internodes $=\mathrm{I} \mathrm{cm}$.

soft and there is not the usual displacement of vessels by fibres in the joint between the one-year-old and two-year-old segments.

Curve D (average area of cavities in sq. $\mu$ ). In both rhododendron and holly the curve descends from base to apex, indicating that the average cross-area of the vessels is largest at the base of the shoots. In the lower internodes, the new vessels which replace the basal fibres are small in size and their number helps to decrease the average area, though there are still numerous large vessels present. In the leafy region of Rhododendron ponticum a great number of larger vessels are found close outside- the primary xylem, and this causes an increase in the average size, which 


\section{Ilex Aquifolium, L., in Reference to Specific Conductivity. 543}

produces a change in the direction of the curve. This is the most marked in the $\mathrm{B}$ group. It is partly this increase in the area of the cavities which in some shoots causes the second ascent of Curve C ; but it does not bring

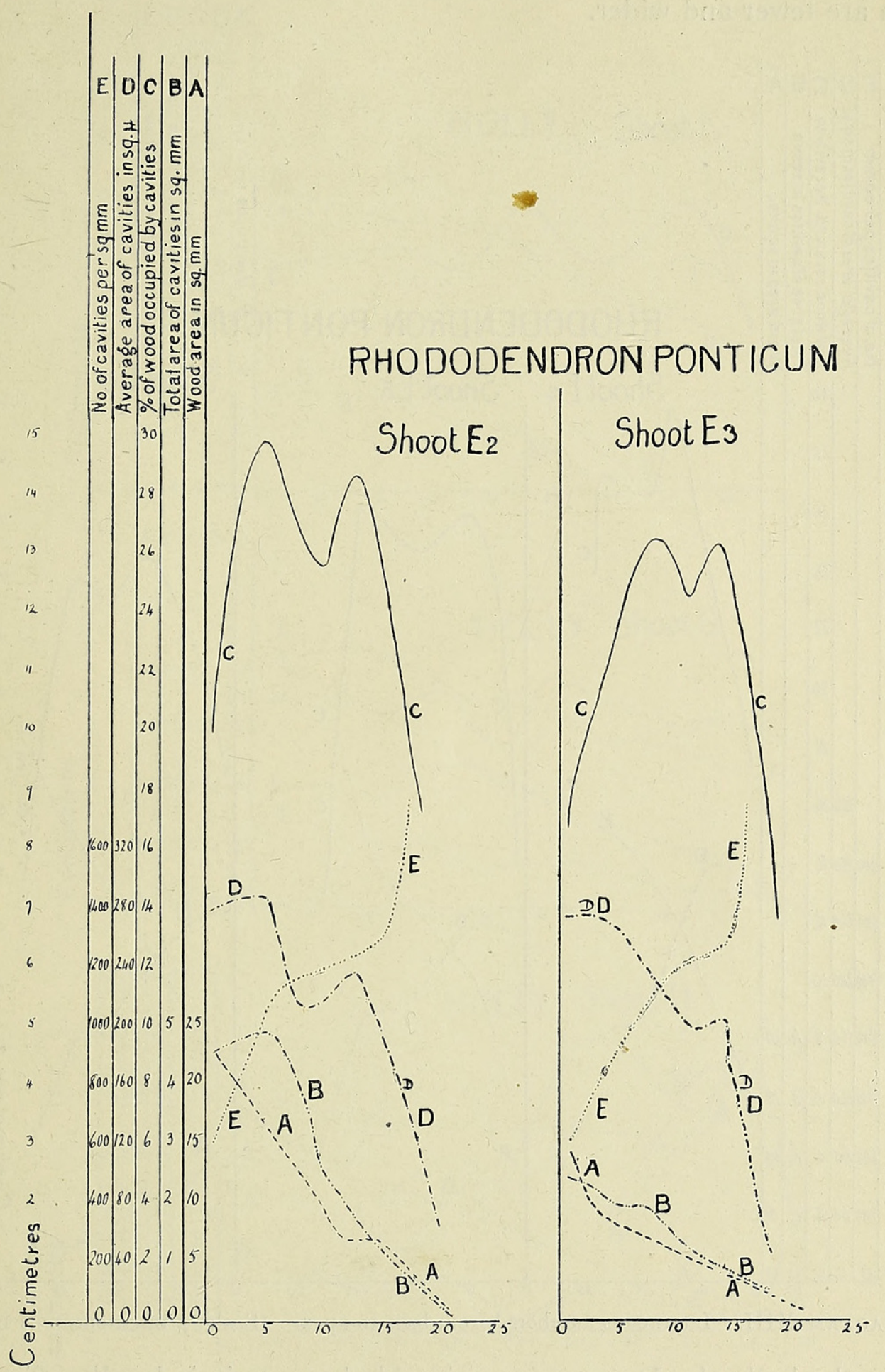

Diagram XII. Internodes numbered from base to apex. (Scale, 5 internodes $=1 \mathrm{~cm}$.)

up the average to the figure reached at the base, because, owing to the decrease in wood-area, the small autumn vessels close to the periphery have a more marked effect on the general average. It should be noticed here 
544 Rivett.-The Anatomy of Rhododendron ponticum, L., and of

that the friction in vessels of small lumina is greater than that in large, and that this will affect the conductivity in the sense that, area for area, it will be lower in vessels which are narrow and numerous than it will be in those which are fewer and wider.

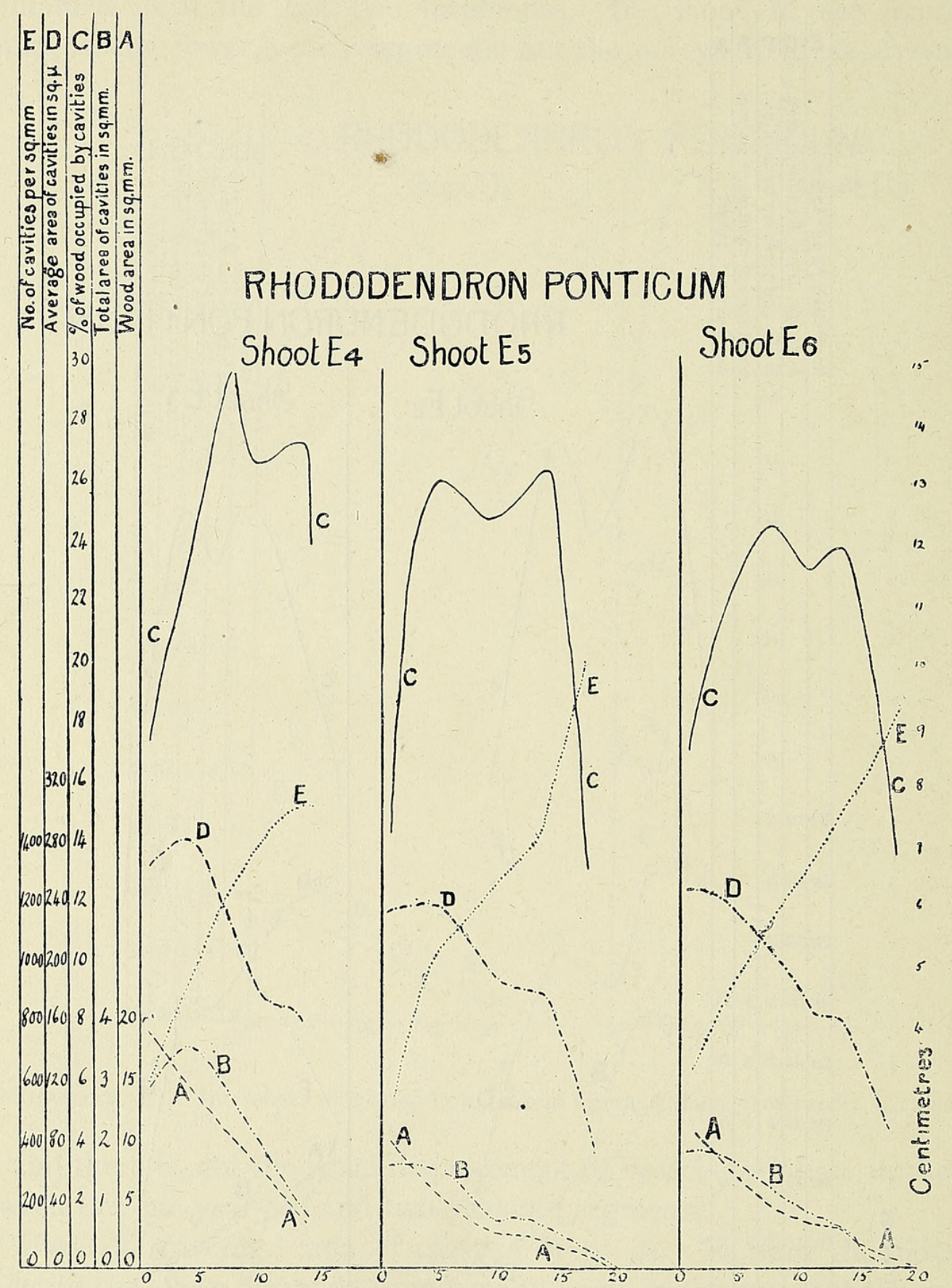

DiAgram XIII. Internodes numbered from base to apex. (Scale, 5 internodes $=\mathbf{I} \mathrm{cm}$.)

In the holly the $\mathrm{D}$ curve is noticeable because it is hardly affected by the yearly joints as are the curves B, C, and E. The highest figures are found at the bases of the oldest shoots, and they become lower in the passage through successive years to the apex. This is due to the fact that the vessels in the outer rings of wood are, on an average, slightly 


\section{Ilex Aquifolium, L., in Reference to Specific Conductivity. 545}

larger than those in the inner rings, but it is also true that in each annual ring the vessels in the more basal internodes of a year's growth are slightly
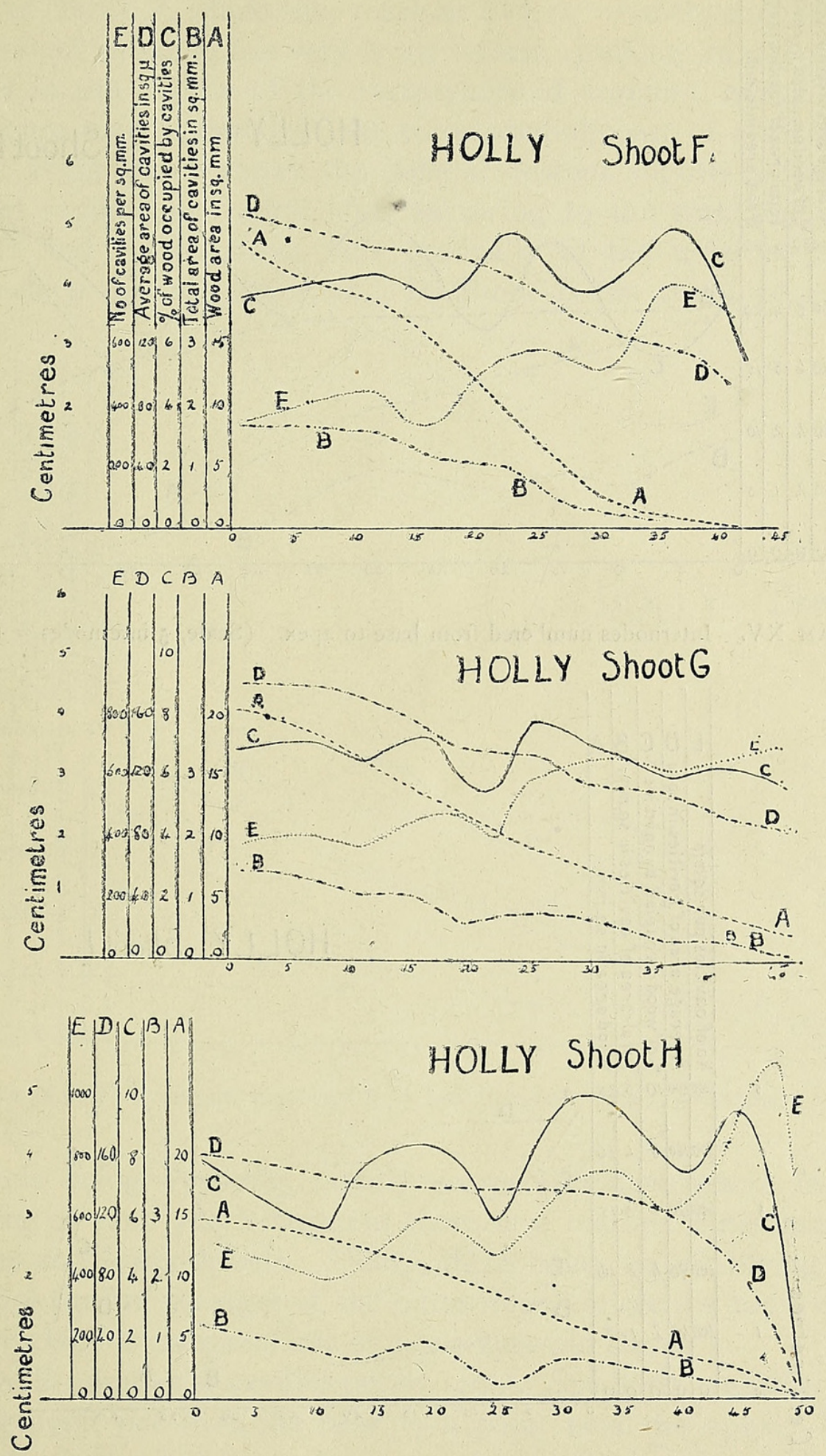

DIAGRAM XIV. Internodes numbered from base to apex. (Scale, 5 internodes $=\mathbf{I} \mathrm{cm}$.)

larger than they are higher up. The last statement is especially true in the first annual ring, where the divergence is quite remarkable. This is illustrated in Diagram III. It is to be observed in the first annual ring 


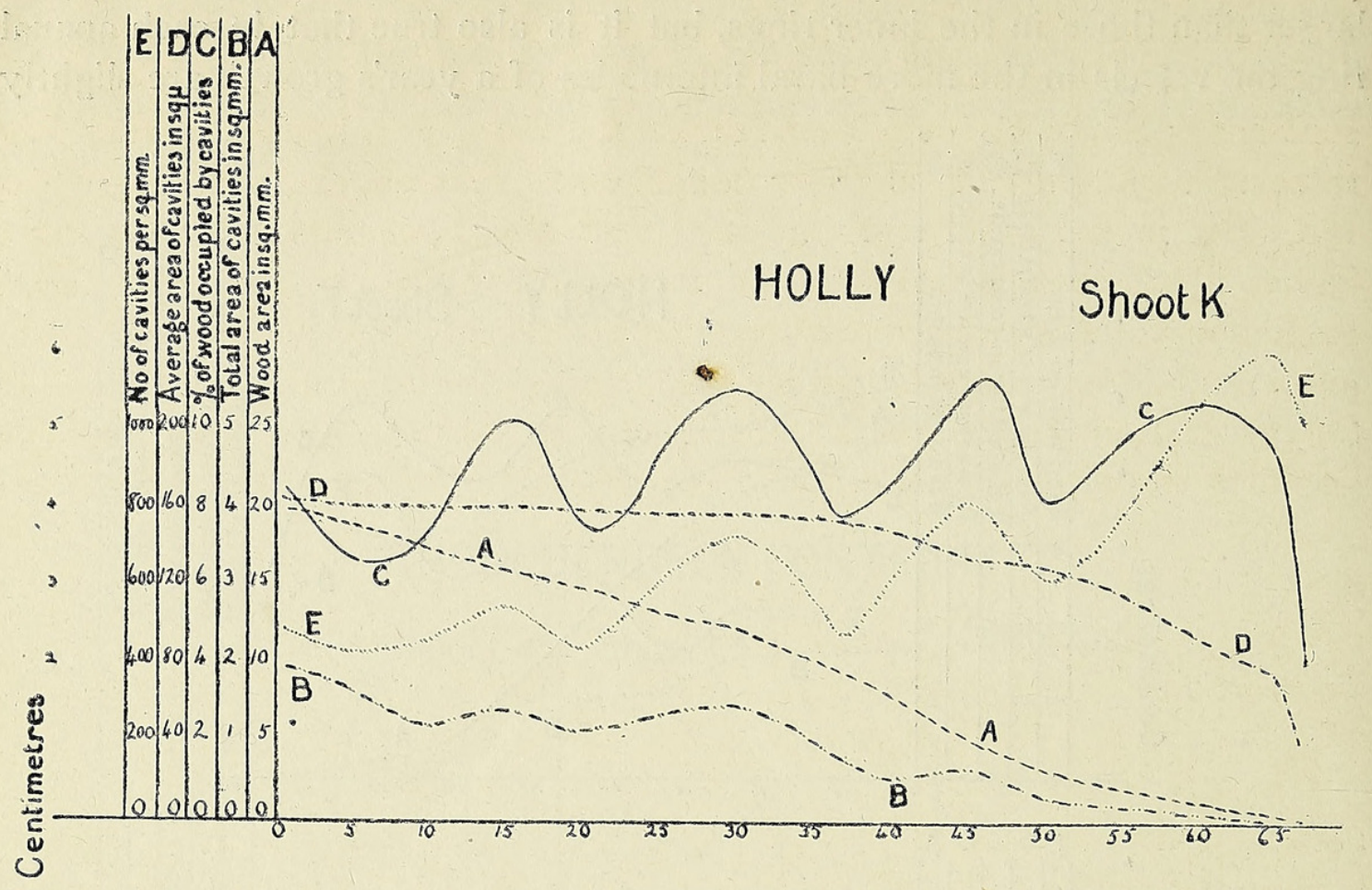

- DIagram XV. Internodes numtered from base to apex. (Scale, 5 intemodes $=1 \mathrm{~cm}$.)

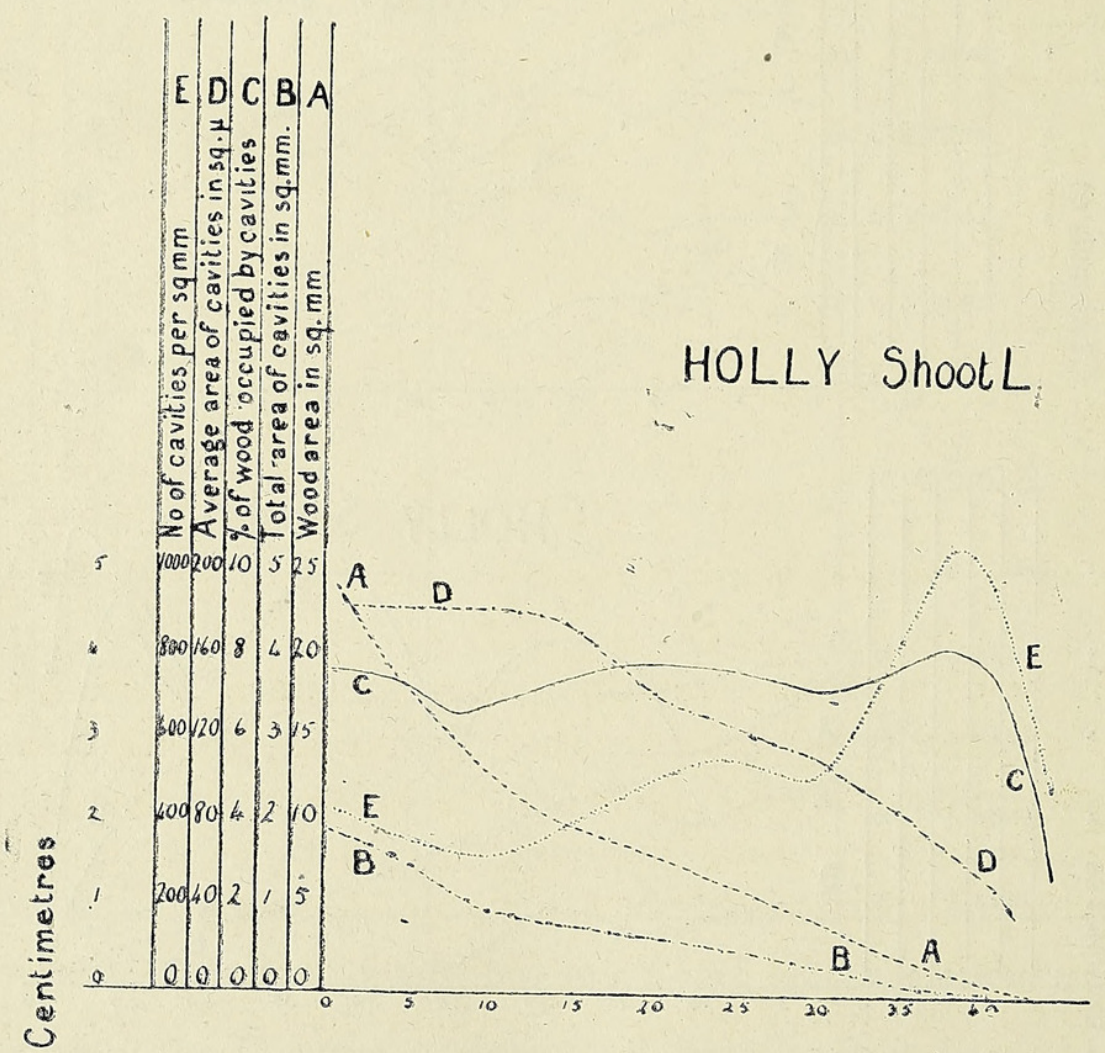

DIAGRAM XVI. Internodes numbered from base to apex. (Scale, 5 internodes $=1 \mathrm{~cm}$.)

that there are one or more large groups of very numerous small vessels occupying certain sectors. These are the conducting elements which connect with the strands of the petiole and the axillary bud: they exert 
a considerable influence on the general average of any particular transverse section. The highest figures are found at the base of the four-year-old segment of Shoot F, where they reach 200 sq. $\mu_{\text {. }} \quad$ For its age, however, the three-year-old shoot $L$ has very large vessels, reaching an average area of I 85 sq. $\mu$ in the middle of the three-year-old segment, which is a much higher figure than is found in the corresponding part of any other shoot. In Shoot $\mathrm{F}$ the curve shows the general descent slightly flattened at the joints and terminating rather high up owing to the truncated apex. In Shoots $\mathrm{H}$ and $\mathrm{K}$ the curve falls gradually in the older segments, but becomes steep towards the apex. In Shoot $\mathrm{L}$ the curve descends more

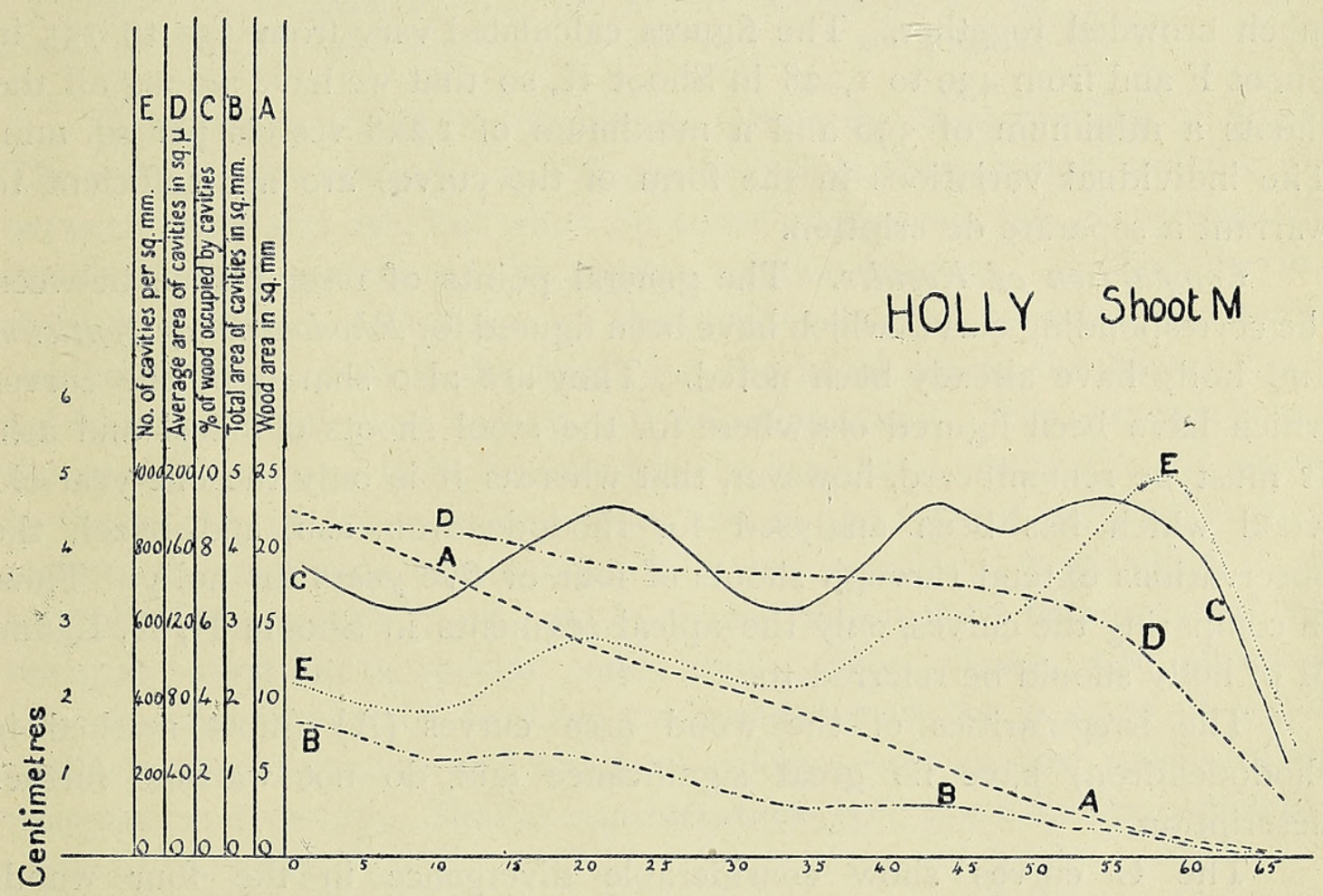

DIAGRAm XVII. Internodes numbered from base to apex. (Scale, 5 internodes $=I \mathrm{~cm}$.)

steeply, this being a young, rapidly grown specimen, where in the first annual ring of each year's segment there is a marked difference between the higher and lower vessels. Hence, there being no modifying influence of the more similar averages of the outer rings, we see the rapid descent of the curve, which is characteristic of a one-year-old shoot.

Curve $\mathrm{E}$ (number of cavities per sq. $\mathrm{mm}$.). Speaking generally the curve shows a general rise from the base to a point near the apex. In Rhododendron ponticum the rise is steep at the base, flattens out slightly in the middle, and becomes steep in the apical internodes. The flattening in the middle indicates a slight falling off in the general increase in number and corresponds with an ascent in Curve $\mathrm{D}$, showing that in this region there are smaller numbers of slightly larger vessels as compared with the region immediately 


\section{Rivelt. - The Anatomy of Rhododendron ponticum, L., and of}

below. The rise at the base corresponds with the rise in Curve $\mathrm{C}$, showing that the first increase in vascular tissue is due to an increase in number. The steep rise at the apex is not shared by Curve C, showing that here the increased number of vessels will not make up for their small lumina from the point of view of water-conduction. The figures calculated vary from 556 at the base of Shoot E 5 to I,908 at the apex.

In holly the most marked characteristic of the $\mathrm{E}$ curves is the sudden fall at each yearly joint. The fall is due, as already indicated, to the large number of fibres developed in those internodes between the winter-bud scales. In reality, though they occupy several nodes, their influence in the length of the stem is very slight, because at these regions the nodes are much crowded together. The figures calculated vary from 330 to 755 in Shoot F and from 439 to 1,228 in Shoot K, so that we have among all the shoots a minimum of 330 and a maximum of 1,228 vessels per sq. $\mathrm{mm}$. The individual variations in the form of the curves are not sufficient to warrant a separate description.

Comparison of Results. The general points of resemblance between the corresponding curves which have been figured for Rhododendron ponticum and holly have already been noted. They are also shared by the curves which have been figured elsewhere for the stool shoots of hazel and ash. It must be remembered, however, that whereas it is only the one-year-old wood which has been analysed for rhododendron, ash, and hazel, the observations extend through shoots of four or five years for holly. Thus, in comparing the curves, only the apical segments in Shoots $\mathrm{H}, \mathrm{K}, \mathrm{L}$, and M of holly should be referred to.

The irregularities of the wood area curves (A) (most marked in rhododendron) have no great significance and do not warrant further description.

The C curves show considerable divergence in the four woods examined. In rhododendron and holly they rise steeply from the base of the one-year-old segments. The maximum in holly is reached more or less in the middle, but generally nearer the apex than the base. The maximum in rhododendron may be reached either nearer the base or nearer the apex: in several cases the maximum is reached nearer the apex on account of the increase in size of the vessels in the leafy part of the stem. The holly is a comparatively small-keaved plant, and the vessels in the stem which link on to those in the petiole are much smaller than the normal found at other levels, while in rhododendron this is not so. Also in the holly the separation of each year's growth into a leafless and leafy region is not nearly so marked as it is in rhododendron; the transitional leaves are comparatively few in number, and permanent foliage leaves may be found at the lower nodes; thus the anatomy in holly shows less variations in analysis than does the rhododendron. 
The actual figures obtained for the $\mathrm{C}$ curve are higher for rhododendron than for holly, ash, or hazel: thus we have

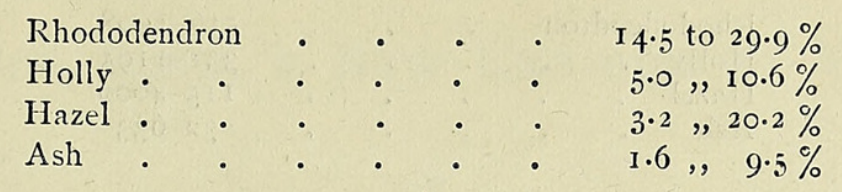

Professor Farmer's figures for the specific conductivity as determined experimentally are as follows:

\begin{tabular}{|c|c|}
\hline Rhododendron ( $\mathrm{A}$ I to $\mathrm{E} 6$ ) & Ir. $9,, 2$ I. $8 \%$ \\
\hline Holly & $11.0 \%$ \\
\hline Hazel . & $22.0,40.0 \%$ \\
\hline Ash & $4.0,24.0 \%$ \\
\hline
\end{tabular}

There seems a certain difficulty in correlating these two sets of figures. The relation between holly and rhododendron is clear enough, and also that between hazel and ash, but when we come to compare the evergreens with the deciduous trees there is no similar relation holding. In rhododendron there is a higher percentage of the wood occupied by water-conducting elements than there is in the hazel, but the hazel shows the higher figures for water-conduction as carried out experimentally. The explanation of the anomaly may partially be found in the lengths of the continuous vessels, in the lengths of the vessel-segments, and in the type of perforation which renders the segments continuous. The very considerable variation in the lengths of the vessels $(5-16 \mathrm{~cm}$.) in rhododendron is to be correlated with the great variation in specific conductivity: short vessels with numerous unperforated cross-walls increase the resistance to the passage of water: similarly, short segments and small scalariform pores increase resistance and decrease conductivity. Similar considerations hold good for the conducting tissue of the holly.

In comparing the relative average cross-areas of the vessels in the four types of wood examined, we have the following data:

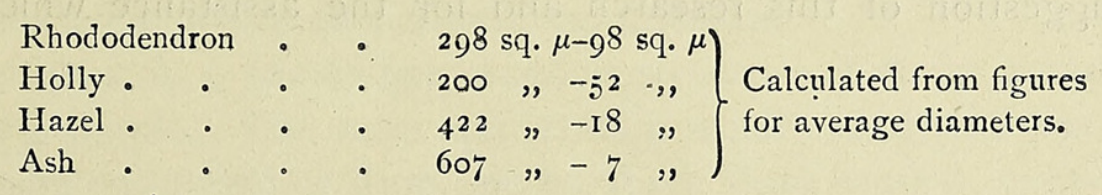

Thus the vessels in the stool shoots of the deciduous ash and hazel have on the whole a much larger average cross-area than those of the evergreen rhododendron and holly: this accounts in a small degree for the high conductivity of the hazel and its relatively low percentage figures, because friction and resistance are less in wide vessels than in those with small lumina. Similarly, the high percentage figures in the rhododendron are partially explained by the smaller lumina of the individual vessels. 
In comparing the values for the number of watei-conducting elements per sq. mm. we have the following :

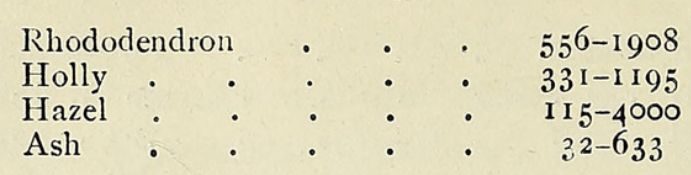

From this little can be deduced except that the extreme figures for hazel cannot be representative of any great length of the stem, because, although the average cross-area of its water-conducting elements reaches a higher maximum than in rhododendron, and although the figure for the maximum number of conducting elements is extremely high, yet the values for the $\mathrm{C}$ curve fall lower than they do for rhododendron. Obviously the balance between size and number for securing maximum conductivity is very delicate and is achieved in hazel rather than in rhododendron, but in the end we are forced to conclude that it is the length of the vessels rather than this balance which is the important factor in conductivity.

\section{Conclusion.}

The results obtained from the quantitative analysis of the wood in Rhododendron ponticum and the holly have been described and correlated with the results given by experiments on their specific conductivity. An attempt has also been made to compare the ascertained data with those given elsewhere for the stool shoots of hazel and ash. The comparison indicates that the evergreen shrubs examined have, as a characteristic of their wood, vessels of a smaller bore and shorter length than those of the deciduous hazel and ash. At the same time all four agree in the fact that there is a general decrease in absolute conductivity from the base upwards in each year's growth, while there is an increase in specific conductivity from the base up to a point near the apex of each year's growth.

In conclusion I wish to express my thanks to Professor Farmer both for the suggestion of this research and for the assistance which he has rendered. 


\section{$2 \mathrm{BHL}$ Biodiversity Heritage Library}

Rivett, Maud F. 1920. "The anatomy of Rhododendron ponticum, L., and of Ilex aquifolium, L., in reference to specific conductivity." Annals of botany 34, 525-550. https://doi.org/10.1093/aob/os-34.4.525.

View This Item Online: https://www.biodiversitylibrary.org/item/236972

DOI: https://doi.org/10.1093/aob/os-34.4.525

Permalink: https://www.biodiversitylibrary.org/partpdf/320306

\section{Holding Institution}

Smithsonian Libraries

\section{Sponsored by}

Biodiversity Heritage Library

\section{Copyright \& Reuse}

Copyright Status: Not in copyright. The BHL knows of no copyright restrictions on this item.

This document was created from content at the Biodiversity Heritage Library, the world's largest open access digital library for biodiversity literature and archives. Visit BHL at https://www.biodiversitylibrary.org. 